\title{
Kinship in Action: Self and Group
}

Andrew Strathern and Pamela Stewart. 2011. Prentice Hall Publishing, Upper Saddle River, N.J. Pp. 224. US \$39.60 (paper). ISBN 100131844849.

Reviewed by Farid Pazhoohi

Reviewer address: 2nd Floor, Baharan Street-Moali Abad Street, Shiraz, Iran. pazhoohi@gmail.com

Kinship in Action is a descriptive and comprehensive investigation of family, marriage, and other kinship related notions that provides us with ethnographic accounts from many different parts of the world. The text also provides us with a historical background of kinship studies and an appreciation of the importance of kinship. Through this book, Andrew Strathern and Pamela J. Stewart support their explanations of kinship-related phenomena with colorful examples from a variety of field sites such as Papua New Guinea, Scotland, Ireland, Austronesian Southeast Asia, China, and Taiwan.

Kinship in Action investigates the question of how individuals relate to one another in group contexts from an anthropological point of view. "Understanding of the basic processes in the domain of kinship is therefore vital to the understanding of the wider domains of politics and history" (p.76).

In the first chapter, Strathern and Stewart define kinship related concepts and highlight the importance of an individual's relation within a group. They state, "It is the intertwining of self and group that interests us and this intertwining can imply conflict as well as cooperation" (p.1) and suggest how kinship broadens from merely a biological phenomenon to a factor building up and affecting social and political relations.

In the second chapter, the authors investigate the "events related to creation, development, maintenance, and termination of kin ties" (p.7) which are elementary structures of kinship in the forms of birth, maturation, marriage, reproduction, and death. The importance of these events could be seen in different rituals as the "prime indicators of social processes and cultural values" (p.18). We learn about the importance of the firstborn child as the beginning of a new nuclear family and the social influences that are imposed on siblings due to their order of birth. Then we learn about ways of marking birth events, such as the introduction of newborns to social families through naming of children and religious practices. The rest of the chapter discusses how an individual goes step-by-step from one age-set to the next level, i.e. puberty, growth, maturation, and death. The authors show us how gifts, other payments, and wealth are exchanged between paternal and maternal lines of kin at birth to encourage the growth of children, and how, at incidents of death, kin might claim the body to be buried on their land.

In the third chapter, the topic of parent-child bonds is investigated. The authors compare Euro-American concepts of reproduction with Trobriand Islander concepts. The absence of a belief in the father's contribution in fetus conception among Trobriand Islanders' understandings of reproduction results in a social structure in which matrilineal clans control land and resources. Strathern and Stewart also discuss kinship after the emergence of new reproductive technologies and problems that might emerge due to the separation of mothers' eggs and surrogacy. Also, they discuss different dimensions of adoption and fosterage with examples from the Pacific region showing the formative role of adoption in social structure.

The fourth chapter discusses that aspect of kinship which connects an individual to the people surrounding him and the aspect in which "kin ties build up into whole groups in accordance with rules and practices of social affiliation, or group membership" (p.58). The authors discuss the history of Scottish highland clans as an example for investigating kinship ties linked to group notions. But instead of defining kinship patterns, the authors go through historical 
accounts of the origin and formation of Scottish highland clans, which seems more appropriate for the sixth chapter. After the discussion of Scottish highland clans, Strathern and Stewart explain the basis of social structure in Duna society in Papua New Guinea and how genealogies of a group are recited to prioritize the deployment of wealth and authority to agnates over other members of a group. Next the authors discuss some other Pacific Islanders, such as inhabitants of Mount Hagen area, to show the arrangements of their social structures in comparison to the Duna. Strathern and Stewart show how the Australian colonial period affected urbanization and social structure and resulted in sociopolitical change. After discussing patrilineality in these regions, the authors turn to the communities where matrilineal descent is practiced, such as the Tolai of the mainland of Papua New Guinea, and mention Derek Freeman's records on bilateral descent among the Iban.

In chapter five the authors justify the importance of marriage to kinship, saying it has functions beyond just sex and reproduction. Marriage, they write, is a tool for, "creating or reinforcing alliances between networks of groups of people" (p.87). Marriage maintains the balance in group relationships and could be used as a tool for managing property and inheritance. In Mount Hagen "marriages are arranged outside of the sphere of recognized kinship around the degree of third cousins" (p.87) to reinforce more distant familial bonds. The authors explain the historical background for Mount Hagen marriage practices to point out the influence of colonial administration on native social structure.

In Kinship in Action, the relations of people to property, land, and resources are emphasized as fundamental factors in kinship. Because of this constellation of concern, the authors tend to stray from their discussions of kinship structures and focus more on the economics. For example, the authors introduce us to the marriage conditions in Telefomin, a small village in which marriage is endogamous, and show how Telefomin marriage arrangements were affected by colonialism. Strathern and Stewart, in their discussion of marriage, filiation, and descent in $\mathrm{Na}$ communities, show how officials encouraged $\mathrm{Na}$ to adopt monogamy and the nuclear family model instead of continuing their matrilineal residential practices.

In the seventh chapter Strathern and Stewart review diverse family and kinship arrangements in the
Appalachian valleys of North America, Newcastle of Australia, Tory Island in Ireland, and Sarakatsani of Greece as examples of kinship studies in America and Europe. And in the last chapter, using an analytical approach, the authors review changes that have occurred due to new practices such as homosexual marriage or surrogacy regarding kinship. Also showing difficulties for specification about relatives, they suggest transaction in substances, food, land, and biological procreation as important notions for relatedness.

Kinship in Action is full of examples from diverse societies. Each chapter finishes with a short conclusion section. The main shortcoming of book is a lack of recognizable and general theoretical conclusions. However, this could be due to the number and diversity of topics that the authors try to cover in just one volume. 